\title{
Problems and Green Development Countermeasures of Pastoral System on the Mongolian Plateau
}

\author{
Suocheng Dong ${ }^{1, *}$, Zehong $\mathrm{Li}^{1}$, Fujia $\mathrm{Li}^{1}$, Hao Cheng ${ }^{1}$, Bing Xia ${ }^{1}, \mathrm{Yu}$ \\ $\mathrm{Li}^{1}$, Wenlong $\mathrm{Li}^{1,2}$, Jingwen $\mathrm{Li}^{1}$, Yang Yang ${ }^{1}$, Fei $\mathrm{Li}^{1}$, Altanbagana \\ Myagmarsuren $^{3}$, Qian Liu ${ }^{1}$ \\ ${ }^{1}$ Institute of Geographic Sciences and Natural Resources Research, Chinese Academy of Sciences, Beijing, \\ China \\ ${ }^{2}$ Resources and Environment Economy College, Inner Mongolia University of Finance and Economics, Inner \\ Mongolia, China \\ ${ }^{3}$ Institute of Geography and Geoecology, Mongolian Academy of Sciences, Ulaanbaatar, Mongolia \\ *Corresponding author. Email: dongsc@igsnrr.ac.cn
}

\begin{abstract}
Mongolian Plateau is a typical pasture industry area in the world. However, due to the impact of global climate change, economic development and market-oriented reform, the pastoral system in the Mongolian Plateau is facing the double challenges of economic development and ecological environment construction. Based on the "herder-livestock-pasture" trinity pastoral system, this study analyzed the typical pasture industry areas in the Mongolian Plateau, and pointed out that there are three main problems in the current pastoral system in the Mongolian plateau: the pastoral system was fragile and sensitive; single industrial structure and severe grassland degradation; disasters occur frequently, and cross-border transmission has a far-reaching impact. The authors put forward four strategies for the green development of pastoral system in the Mongolian Plateau. Namely, general model of ecological civilization; optimize industrial structure and develop green recycling industry; strictly follow the ecological red line and coordinate to promote transnational ecological protection; strengthen international cooperation and explore the implementation of green development system construction. This article aimed to provide new ideas for the green development of pastoral system and the protection of global ecological security in the Mongolian plateau.
\end{abstract}

Keywords: Mongolian plateau, global climate change, pastoral system, green development, problems and countermeasures

\section{INTRODUCTION}

The Mongolian Plateau is located in the hub area of the China-Mongolia-Russia Economic Corridor and is the north-south strategic channel connecting the first Eurasian continental bridge-Siberian railway and the second Eurasian continental bridge [1]. Pasture is an important pillar industry with a long history on the Mongolian Plateau, and it includes one of the most important human activities on the Mongolian Plateau. It has formed a closely connected and interactive "herder-livestock-pasture" trinity pastoral system. However, due to factors such as population growth, economic development and land use change, the sustainable development of pasture industry is facing severe challenges, especially aggravated by climate change [2]. Climate change disrupts the balance between livestock and grassland vegetation and poses a crisis for the populations that depend on them [3], affecting regional ecological security and sustainable human development. As climate change intensifies, outstanding contradictions of pastoral system on the Mongolian Plateau have received considerable attention $[4 ; 5]$. The previous studies on the pastoral system and climate change mainly included the response of pastoral system to climate change [6;7], the comprehensive response of the pastoral system to climate change and economic and social factors [8], vulnerability assessment of pastoral systems to climate change [9]. The problems faced by the pastoral systems on the Mongolian 
Plateau have not been systematically analyzed. Based on the team's long-term investigation results, this paper selected Bayanhongger, Dundgovi Xilingrad and Ulanqab as case areas to comprehensively analyze pastoral systems on the Mongolian Plateau, and put forward the countermeasures for the green development of pastoral systems. This paper has important theoretical and practical significance for promoting the green development of pastoral system and protecting the overall ecological security of the Mongolian Plateau.

\section{STUDY AREA}

Bayanhongger is located in the southwest of Mongolia, with an average annual temperature of $1.5^{\circ} \mathrm{C}$ and an average annual rainfall of $172.2 \mathrm{~mm}$. Dundgovi is located in the middle of Mongolia, with an average annual temperature of $3.2^{\circ} \mathrm{C}$ and an average annual precipitation of $118.2 \mathrm{~mm}$. These two case areas are important pastoral areas in southcentral Mongolia, and the added value of animal husbandry in both provinces accounted for more than 50 percent of GDP in 2019. In the past 10 years, the livestock capacity of Bayanhongger had increased from 1.963 million to 4.645 million, and that of Dundgovi from 1.112 million to 4.093 million.

While the rapid development of pasture industry in this region promotes regional economic growth, the contradiction between pasture industry and ecological environment protection is becoming increasingly fierce. Bayanhongger and Dundgovi are typical steppe and desert steppe type areas in Mongolia, with an obvious trend of warming and drying. According to the UN report, $81.2 \%$ of land in Bayanhongger and $87.5 \%$ of land in Dundgovi have been affected by desertification and land degradation.

Located in the middle of the Inner Mongolia Autonomous Region, Xilingrad is the largest natural grassland in China and a representation of the typical grassland in northern China. The average annual temperature in the region is $0-4^{\circ} \mathrm{C}$ and the average annual precipitation is $200-350 \mathrm{~mm}$, which is a temperate continental climate. Located in the central part of Inner Mongolia Autonomous Region, Ulanqab is a typical agro-pastoral ecotone and a representative area of desert steppe. The annual average temperature is $0-6^{\circ} \mathrm{C}$, and the annual average precipitation is 150 $\mathrm{mm}$ - $450 \mathrm{~mm}$. In recent years, Xilingrad and Ulanqab have actively explored the "herderlivestock-pasture" trinity pastoral system and established Yili dairy industry chain, mutton sheep green cycle industry chain and beef cattle green cycle industry chain. These models have achieved good social, economic and eco-environmental benefits.
They are examples of active policy interventions to curb grassland degradation. This is different from the case region of Mongolia (Figure 1).

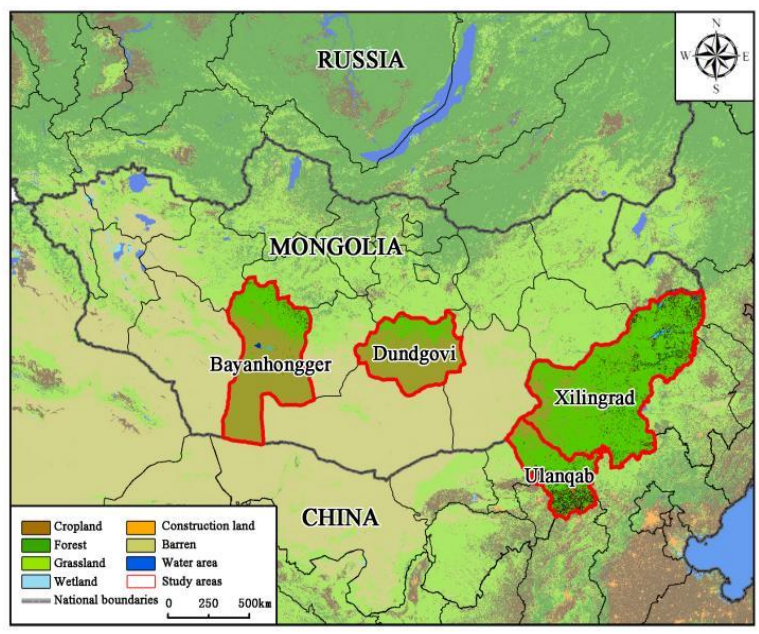

Figure 1. Land cover of typical study areas on the Mongolian Plateau

\section{PROBLEM}

\subsection{The pastoral system was fragile and sensitive}

The Mongolian Plateau is an important physical geographical unit in the hinterland of Eurasia and a unique ecological environment in the transitional zone between arid and semi-arid climate. The climate is arid and rainless. The vegetation coverage from north to south across the forest, forest steppe, typical steppe, desert steppe, Gobi desert and typical steppe. The ecological environment is diverse but relatively fragile, and it is extremely sensitive to climate change [10]. Under the background of global climate change, with the change of temperature and precipitation pattern and the influence of extreme climate events, population growth, policy, livestock number and grazing mode had a profound impact on grassland productivity, livestock-pasture balance and sustainable development ability, which have greatly destroyed the balance among the three elements of the "herder-livestock-pasture" pastoral system. It aggravated the overall vulnerability of pastoral system on the Mongolian Plateau.

\subsection{Single industrial structure of pasture industry, severe grassland degradation}

Pasture industry is a pillar industry for the economic and social development of the Mongolian Plateau, and it is an economic source for the survival of the majority of herders. Especially in Mongolia, 
the ratio of the added value of animal husbandry to GDP has always been in a leading position for many years. Since the implementation of private ownership reform in Mongolia, the number of livestock has been increasing continuously, from over 20 million in 1990 to 71 million in 2019. While breaking through the ecological environment capacity of pastoral areas, it also further aggravated the fragility of Mongolian pastoral system. This has formed a vicious circle of "climate change $\rightarrow$ grassland degradation $\rightarrow$ decreased livestock capacity $\rightarrow$ decreased economic benefits $\rightarrow$ decreased herders' income $\rightarrow$ increased livestock scale $\rightarrow$ overgrazing $\rightarrow$ increased pasture degradation ". The ability of regional sustainable development has been severely weakened, the transformation of industrial structure and social progress have been slow, and the region has been in the stage of social development of agriculture and pasture industry for a long time.

Meanwhile, the temperature in Mongolia increased by $2.04^{\circ} \mathrm{C}$ from 1940 to 2019. From 1942 to 2018 , the annual average precipitation decreased by $7 \%$. The drought and water shortage caused by the warm-drying trend has had a direct and huge impact on the pastoral system of the Mongolian Plateau. This has further exacerbated the degradation risks of the Mongolian Plateau grasslands.

\subsection{Natural disasters occur frequently and the cross-border transport of dust has a far- reaching impact}

Climate change and the traditional pasture industrial production mode of over grazing have greatly destroyed the balance among the three elements of the "herder-livestock-pasture" pastoral system. This mode of production also intensifies the overall vulnerability of the pastoral system on the Mongolian Plateau, which is one of the main reasons for the frequent occurrence of dust storms and ecological degradation on the Mongolian Plateau. In the past 60 years, the number of extreme weather on the Mongolian Plateau has increased, and the number of sandstorms, snow disasters, cold waves and other disasters on the edge of the Gobi in Mongolian Plateau has increased. The average annual strong dust weather in Mongolia in the 1990s had reached 56 days, about four times that of the 1960s. By 2015, the number of days of strong sand and dust in the Gobi Desert in Mongolia had generally reached 70-120 days, causing great pollution to the ecological environment.

Mongolia and China's Inner Mongolia Autonomous Region belong to the Mongolian Plateau, and both belong to the entire arid and semi- arid terrestrial ecosystems of Asia. In the context of global change, Mongolian Plateau's atmospheric circulation, environmental evolution, natural disasters and human activities have continuously intensified the impact on our country. As Mongolia's desertification continues to intensify, the cross-border transmission of sandstorms will continue to pose a serious threat to the ecological security of northern China. From March 14 to 19 and 27 to 29, 2021, a severe sandstorm disaster originating in Mongolia swept across the central and southern part of Mongolia, resulting in 6 deaths, more than 80 missing, 1.6 million livestock lost, 69 houses roofs blown off, and 92 houses and 587 fences collapsing. Cross-border transmission covers 177 prefecturelevel cities in northwest, north and northeast of China, causing great pollution to the north of China. It is the most intense and extensive sandstorm in China in the past decade. Another sandstorm occurred in the south-central part of Mongolia in May and June 2021, and cross-border transport endangered Inner Mongolia.

\section{COUNTERMEASURE}

\subsection{General model of ecological civilization}

Ecological civilization is a new form of human civilization in which man and nature live in harmony. It actively advocates the concept of ecological civilization, applies green technology, explores the "two high, three low" development model of low input, high output, high benefit, low consumption and low pollution [11], and jointly builds a demonstration zone for ecological civilization and green development cooperation on the Mongolian Plateau. To build a six-in-one ecological civilization system of the Mongolian Plateau, we should take the protection of ecological space as the basic premise, the good ecological environment as the important support, the prosperous ecological economy as the main driving force, and the advanced ecological culture as the ideological guidance, take the perfect ecological civilization system as the important guarantee, take the high-quality ecological human settlements as the beautiful home.

\subsection{Optimize Industrial structure and develop Green Recycling Industry}

Establish a green eco-economic system on the Mongolian Plateau to achieve the coordination of human-land relationship and the high-quality development of green low-carbon cycle. Establish a number of eco-economic demonstration bases and 
pastoral system circular industrial parks on the Mongolian Plateau, give preferential support policies, and comprehensively reduce ecological pressure through the transformation and upgrading of the industrial structure of the whole basin to the direction of green circulation and high quality (Figure 2).

Human activities such as deforestation [12], wasteland reclamation, overgrazing and large-scale mining are strictly prohibited in the ecologically fragile areas of the Mongolian Plateau. Actively promote the prohibition of grazing, rest grazing, and area rotation grazing to restrict grazing activities, adjust the structure of the pasture industry and livestock grazing methods; adopt seasonal pastures, reasonably control the number of livestock, and avoid overgrazing. Relying on the advantages of transfer payment and policy support in the ecological zone, actively develop eco-tourism, carbon sink industry, etc., and create a characteristic eco-industry system. Vigorously develop the deep processing of pasture industry products, improve the added value of pasture industry products, promote the process of industrialization by developing the upstream and downstream industrial chains of pasture industry [13], provide employment opportunities for local farmers and broaden the employment channels of farmers and herdsmen. In addition, in agricultural planting areas, the planting structure should be optimized and the cultivation of crops with high water consumption should be strictly controlled. Strengthen the construction of green mines, promote cleaner production in the energy industry, and increase resource utilization.

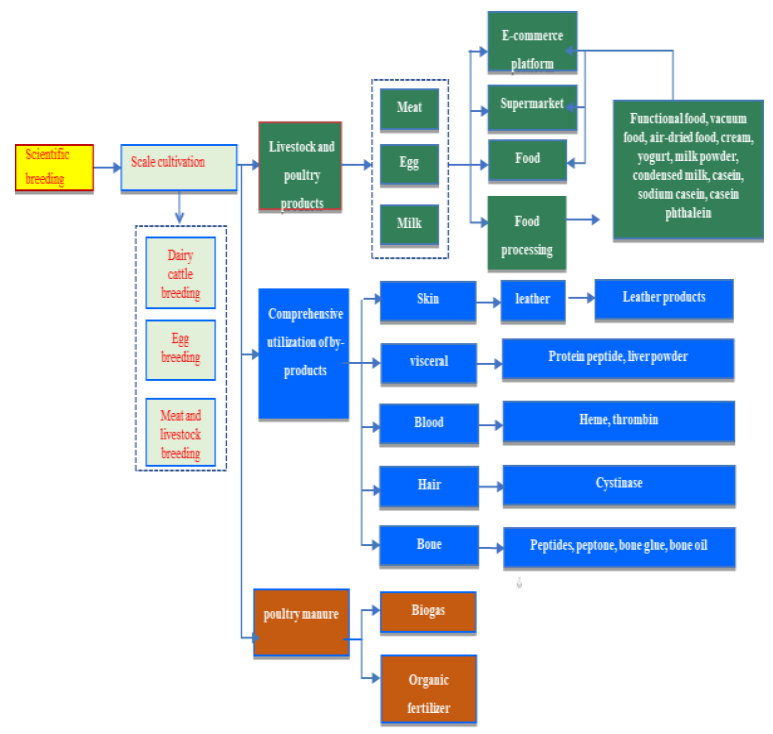

Figure 2. Pastoral system circular industrial parks on the Mongolian Plateau

\subsection{Strictly abide by the ecological red line and coordinate to promote transnational ecological protection}

Strengthen cross-border ecological environmental protection and international cooperation in addressing climate change. Actively lay out and popularize major advanced technological and engineering models for desertification control, solve desertification control problems in various ways, actively lay out major advanced technological projects for desertification control, such as photovoltaic sand control [4], sandy land water saving and high-efficiency agriculture to solve the problem of desertification control. Innovative breakthroughs, joint efforts to tackle key problems, comprehensive use of biological sand fixation measures and engineering sand fixation measures, implementation of major desert edge locking projects to prevent wind and sand fixation in desert areas where stable greening has not been formed, and the task of stabilizing desert edge greening and edge locking. We will improve the effectiveness of "sand control and green protection" and build an ecological security barrier on the Mongolian Plateau. Innovative breakthroughs, joint efforts to tackle key problems, make comprehensive use of biological sand fixation measures and engineering sand fixation measures, and implement major projects to lock the edge of the desert to prevent wind and fix sand in desert areas where stable greening has not been formed, so as to stabilize the edge of the desert and build an ecological security barrier on the Mongolian Plateau.

\subsection{Strengthen international cooperation and explore the implementation of green development system construction}

With the goal of improving the system of ecological civilization, establish and improve the system of green development of the Mongolian Plateau. Carry out research on grass stock balance and ecological risk early warning on the Mongolian Plateau, build an international cooperation platform for ecological risk prevention and control between governments, jointly build an ecological risk monitoring network and an international scientific laboratory for ecological risk prevention and control, and strengthen the vulnerability assessment of the Mongolian Plateau animal husbandry system and real-time monitoring. Establish an ecological risk information exchange and sharing service mechanism, and strengthen the notification, communication and joint prevention and management of key ecological disasters in cross-border areas. 
Prevention and control of cross-border transmission of disasters to minimize cross-border losses. Advocate the core values of ecological culture [14], set up the human values of green development from the ideological concept, and fundamentally realize the harmonious coexistence of man and nature. The convention on the construction of a green system on the Mongolian Plateau focuses on international conventions focusing on cross-border forest and grassland ecosystem protection, green government, corporate environmental responsibility and public participation.

\section{CONCLUSIONS}

In this study, we use a combination of qualitative and quantitative methods, select typical case areas, and analyze the impact of different policies on animal husbandry in the Mongolian Plateau of the same geographical unit. It is found that the vulnerability of animal husbandry system in the Mongolian Plateau is significant; the animal husbandry industry in the Mongolian Plateau is single, and the grassland is seriously degraded; Natural disasters occur frequently in the Mongolian Plateau, and the cross-border transmission of sand and dust has a far-reaching impact. In view of the above problems, drawing on China's experience in grassland ecological governance and animal husbandry industry development over the years, this paper puts forward the general model of ecological civilization development, optimizes the industrial structure, develops green circular industry, strictly abides by the ecological red line, cooperatively promotes transnational ecological protection, strengthens international cooperation, and explores and implements the construction of green development system, It provides a scientific basis and path for the development of animal husbandry and ecological environment protection in the Mongolian Plateau.

\section{ACKNOWLEDGMENTS}

This work was supported by Green Development Mode and Typical Demonstration of ChinaMongolia-Russia Economic Corridor (ANSO-CRKP-2020-02), the National Social Science Fund of China (17VDL016), the Science \& Technology Basic Resources Investigation Program of China (2017FY101304), National Natural Science Foundation of China (Grants 41911530103, 41701639), and Key deployment project of Chinese Academy of Sciences (ZDRWZS201812).

\section{REFERENCES}

[1] Dong, S. C., Yang,Y., Li,F. J.,et al,2018. An evaluation of the economic, social, and ecological risks of China-Mongolia-Russia highspeed railway construction and policy suggestions. Journal of Geographical Sciences. 28(7), 900-918. DOI: https://doi.org/10.1007/s11442-018-1512-y

[2] Cai Lujia, an Pingli, Liu Yingcheng, Wang Fangtian, Li Xuemin, Huang Xinxin. 2017.Study on the moderate intensive utilization of cultivated land in the agro pastoral ecotone of Inner Mongolia under the constraints of water resources -- a case study of Ulanqab City. Resources and environment in arid areas, 31 (05): 81-87 (in Chinese).

[3] Zhang Peifeng, $\mathrm{Hu}$ Yuanman, Zhao Minghua.2010. Study on the mechanism of economic development and ecological environment in Ulanqab City . Resources and environment in arid areas, 24 (03): 6-12 (in Chinese).

[4] Reidsma P, Ewert F. 2008.Regional farm diversity can reduce vulnerability of food production to climate change. Ecology and Society,.13: $38 . \quad$ DOI: https://doi.org/10.5751/ES-02476-130138

[5] Cobon DH, Stone GS, Carter JO, et al.2009. The climate change risk management matrix for the grazing industry of northern Australia. The Rangeland Journal, 31: 31-49. DOI: https://doi.org/10.1071/RJ08069

[6] Taylor W, Hart I, Pan C, et al.2021. High altitude hunting, climate change, and pastoral resilience in eastern Eurasia. Scientific Reports, 11, 14287. DOI: https://doi.org/10.1038/s41598-02193765-w

[7] Godde CM, Bonne RB, Ash AJ, et al. 2020.Global rangeland production systems and livehoods at threat under climate change variability. Environmental Research Letters, 15(4), $044021 . \quad$ DOI: https://doi.org/10.1088/1748-9326/ab7395

[8] Liu Y, Zhang Z, Tong L, et al. 2019.Assessing the effects of climate variation and human activities on grassland degradation and restoration across the globe. Ecological Indicators, $\quad 106: 105504 . \quad$ DOI: https://doi.org/10.1016/j.ecolind.2019.105504 
[9] Smit B, Wandel J. 2006.Adaptation, adaptive capacity and vulnerability. Global Environmental Change, 16: 282 -292. DOI: https://doi.org/10.1016/j.gloenvcha.2006.03.008

[10] Nori M, Davies J.2007. Change of wind or wind of change? Climate change, adaptation and pastoralism. The World Initiative for Sustainable Pastoralism, International Union for Conservation of Nature, Nairobi, Kenya.

[11] Ecology - Landscape Ecology; 2020.Jiangxi University of Finance and Economics Researchers Report Recent Findings in Landscape Ecology (Coupled Relationship between Rural Livelihoods and the Environment at a Village Scale: A Case Study in the Mongolian Plateau)[J]. Ecology Environment \& Conservation.
[12] Fan Peilei,Chen Jiquan,John Ranjeet. 2016, Urbanization and environmental change during the economic transition on the Mongolian Plateau: Hohhot and Ulaanbaatar.[J]. Environmental research, 144. DOI: https://doi.org/10.1016/j.envres.2015.09.020

[13] Qian Zhang.2011.Herders' Social Vulnerability to Climate Change: A case of desert grassland in Inner Mongolia[J].Sociological Studies,26(06):171-195.

[14] Rina Su,Tao Yu,Buddhi Dayananda,Rentuya Bu,Jinhua Su,Qingyun Fan.2020. Impact of climate change on primary production of Inner Mongolian grasslands[J]. Global Ecology and Conservation, 22 . DOI: https://doi.org/10.1016/j.gecco.2020.e00928 